\title{
A Study on the Comfort and the Patternmaking Method of Leggings Pants ${ }^{+}$
}

\author{
Park Sanghee - Park Jinhee* \\ Assistant professor, Dept. of Traditional Korean Costume, Baewha Women's University \\ Lecturer, Dept. of Knit Fashion Design, Hanyang Women's University*
}

\begin{abstract}
Fabric industry has been developing enough to introduce diverse stretch materials to apparel market, so that tightly fitting leggings designs are taking over not only sports wear but also women's clothing. This study is aimed at developing prototype designs for leggings pants using stretch material that are appropriate for the lower part of body being functional, comfortable, and beautiful. As well, the study is intended to be of a reference in manufacturing such products.

Some of the most popular leggings on the market in their kinds and materials were primarily selected to be tested in two ways: wear test and appearance test. Again, the test pants went through the same kinds of two tests, which turned out two designs. Finally, the test pants were treated to yield the most desirable prototype design. In conducting all these tests, some major defects causing discomfort and shortcomings of the leggings pants on the market were exposed and through the wear tests, the drawbacks were seen to be complemented in a big way. Thus, it is hopefully expected that this study will serve as a good reference for developing stretch pants.
\end{abstract}

Key Words : leggings pants, pattern, comfort, appearance test

\section{The Introduction}

With the development of fabric industry, more and more new elastic materials have been introduced to the market. ${ }^{1)}$ Such new materials are especially loved by young women. Not only for their agreeable comfort, also for the unique fitting when closely pressing the body and incomparable touch and feeling, stretch fabrics are gaining popularity in extensive parts of fashion field, which once was likely to be limited to only sports wear area. ${ }^{2)}$ The preference of

\footnotetext{
${ }^{+}$The contents of this paper will be included in the master's thesis to be published.

Corresponding author: Park Jinhee, Tel. +82-10-8970-4677, Fax. +82-2-821-4677

E-mail: jinnyangel2000@hanmail.net
} 
consumers seems to influence fashion trend to go after more tightly fitting clothes. ${ }^{3)}$ Even skinny jeans are gaining in popularity among the young female population on the back of the preference for slimmer and sexier body lines stemming from the continued weight loss fever. ${ }^{4)}$

Stretch fabrics are pretty much elastic, so that ease must be reconsidered in designing pattern not like designing with regular fabric. The proper studies are necessary on patterns for stretch fabrics considering the characteristics of the material. ${ }^{5)}$ According to the study by Cheil Industries (a leading Korean fabric manufacturer $)^{6)}$, in designing patterns for stretch fabrics, ease should be rendered less than usual considering elasticity. Especially the width of the weft direction of the fabric must be made extra less in case there may be some laxness owing to residual elasticity.

Among many others, the study by Chun, Jong-Suk ${ }^{7)}$ is assumed to be the most acceptable one since the least wrinkles are observed through appearance test on fabrics with similar elongation characteristics for both warp and weft, while other contemporary studies suggest simply reducing the amount of ease on the whole. Jung, Hee-Soon ${ }^{8)}$ in her study of applying stretch fabrics, said that the warp elongation and tension should be considered for taking measurements of vertical direction of the fabric; the weft elongation and tension for level way of the fabric. In spite of all these developments of new materials and studies on designing, apparel in stretch fabrics still has a room for improvement. Especially for pants, discomfort is found around knees, bottoms, and thighs. As well, in appearance tests, low points are given to such parts as rise length, rise girth, hip girth, and overall fitting.

Leggings are a kind of pants that worn frequently nowadays in our daily lives. They come in various designs and are taking root as an essential item for young ladies in their twenties. However, few studies are found on the material and pattern of leggings pants, or on the complaints and defects of them. ${ }^{9)}$ Thus, we are in need of a proper study focussed on developing a prototype of leggings pants that involves adequate functional stretch material with mobile compatibility, and a fair appearance. This study in turn is aimed at understanding current complaints of leggings pants, and developing a prototype of stretch pants with good functionality, comfort and nice appearance; providing a practical reference for manufacturing stretch pants.

\section{The Methods and Process}

\section{Selecting Subjects and Postures}

Five female subjects are selected who are in their early twenties with the average body shapes in the accordance to the figures by Size Korea(2004). ${ }^{10)}\langle$ Table $1>$ is about the body measurements of the subjects. <Figure 3> shows that terms and illustrations of standing, sitting, and squatting postures.

\section{Selecting Leggings on the market and the Wear Test}

Some of the most popular leggings on the market with popular materials and types were selected for the preliminary test. The materials selected for the test were cotton jersey span, cotton twill span, cotton knitted span, and modal. Two types of pants were selected: those with the length to ankles (ankle pants) and those covering the upper feet (open heel pants). The 
Park Sanghee - Park Jinhee / A Study on the Comfort and the Patternmaking Method of Leggings Pants

$\langle$ Table 1$\rangle$ The body measurements of the subjects

\begin{tabular}{c|c|c|c|c|c|c|c}
\hline \hline & \multicolumn{9}{|c|}{ subjects } & \multicolumn{2}{c}{$\begin{array}{c}\text { the average shape } \\
\text { of females in 20s } \\
(\text { Size Korea, 2004) }\end{array}$} \\
\cline { 2 - 8 } & A & B & C & D & E & Mean & Standard Deviation \\
\hline waist girth (cm) & 65.0 & 63.0 & 64.0 & 64.0 & 62.0 & 67.3 & 2.5 \\
\hline hip girth(cm) & 84.0 & 89.5 & 89.0 & 88.0 & 92.0 & 90.8 & 3.1 \\
\hline hip length (cm) & 21.0 & 19.5 & 19.0 & 20.5 & 20.0 & 21.8 & 2.6 \\
\hline crotch length (cm) & 26.5 & 26.5 & 26.5 & 26.5 & 26.5 & 27.2 & 1.8 \\
\hline outside leg length (cm) & 99.5 & 99.0 & 103.0 & 103.5 & 100.0 & 100.2 & 4.0 \\
\hline height (cm) & 162.0 & 162.0 & 162.5 & 162.4 & 161.0 & 160.5 & 2.0 \\
\hline \hline
\end{tabular}

preliminary test was done to find out the preference of the materials, comfort, and functionality. The two materials were chosen that earned the highest scores at the preliminary test, which shown in $\langle$ Table 2〉.

\section{Making Test Pants}

The basic patterns used for manufacturing the test pants are Leggings Pattern by Oh, Sun-Hee ${ }^{11}(A)$, and Jeans Pattern without dart by $E$ SMOD $^{12)}$ (B). <Figure 1> shows that Patterns of the Test Pants: Leggings Pattern by Oh, Sun-Hee ${ }^{11}(A)$, and Jeans Pattern without dart by $E_{S M O D}{ }^{12)}(B)$. These are considered to be the most appropriate patterns for leggings since they fit tight with no darts. Leggings pattern by Oh, Sun-Hee ${ }^{11)}(A)$ has two lines (original line is folded(overlapped) at the center and then final line is clear one in drafting. The two basic patterns were framed with the most comfortable pattern that proved to satisfy a pleasant overall hip girth through the previous wear tests. On the basis of the pattern, three test pants were made - each with the position of the heel openings as 6,7 , and 8 centimeters from the center of the ankles, the points of which are based on the figures in the Standard Body Measurements of Female in 20s.

Each pattern was also made into two kinds of pants using the two materials, cotton jersey span and modal, which were evaluated as the most comfortable ones at the previous tests(The wear test of Leggings Pants on the market: The Preliminary Test). By all the results of the preliminary tests, modal and cotton span materials were proved to be most acceptable by subjects. Thus, test pants are determined to be made of the two materials.

\section{The wear test of the Test Pants}

The wear test for the comfort of the pants was carried out on the same subjects of the preliminary test. Additionally, the appearance test was done on five graduate students majoring fashion design, in which front, back and side appearances were evaluated by five point rating scale. <Figure 2> showed that the types of test pants and the fitting appearance at the front and the back. The evaluations involved the degree of tension at knees and thighs at sitting posture and squatting posture, the degree of tightening around every part, wrinkles in front groin region, sagging around the back waist, comfort of heel openings, and so on. 
$\langle$ Table 2> The selected materials of the pants and the characteristics

\begin{tabular}{|c|c|c|c|c|c|c|}
\hline \multirow[t]{2}{*}{ material } & \multirow[t]{2}{*}{ texture } & \multirow[t]{2}{*}{ composition(\%) } & \multirow[t]{2}{*}{ thickness(mm) } & \multirow[t]{2}{*}{ weight $\left(\mathrm{g} / \mathrm{m}^{2}\right)$} & \multicolumn{2}{|c|}{$\begin{array}{c}\text { elongation } \\
\text { ratio(\%) }\end{array}$} \\
\hline & & & & & warp & weft \\
\hline $\begin{array}{l}\text { cotton- } \\
\text { span }\end{array}$ & jersey & $\begin{array}{c}\text { cotton } 97.0 \\
\text { polyuretan } 3.0\end{array}$ & 0.77 & 223.3 & 44.9 & 35.3 \\
\hline modal & jersey & $\begin{array}{c}\text { Rayon } 76.6 \\
\text { Polyester } 18.2 \\
\text { Polyuretan } 5.2\end{array}$ & 0.46 & 164.1 & 55.9 & 88.5 \\
\hline
\end{tabular}
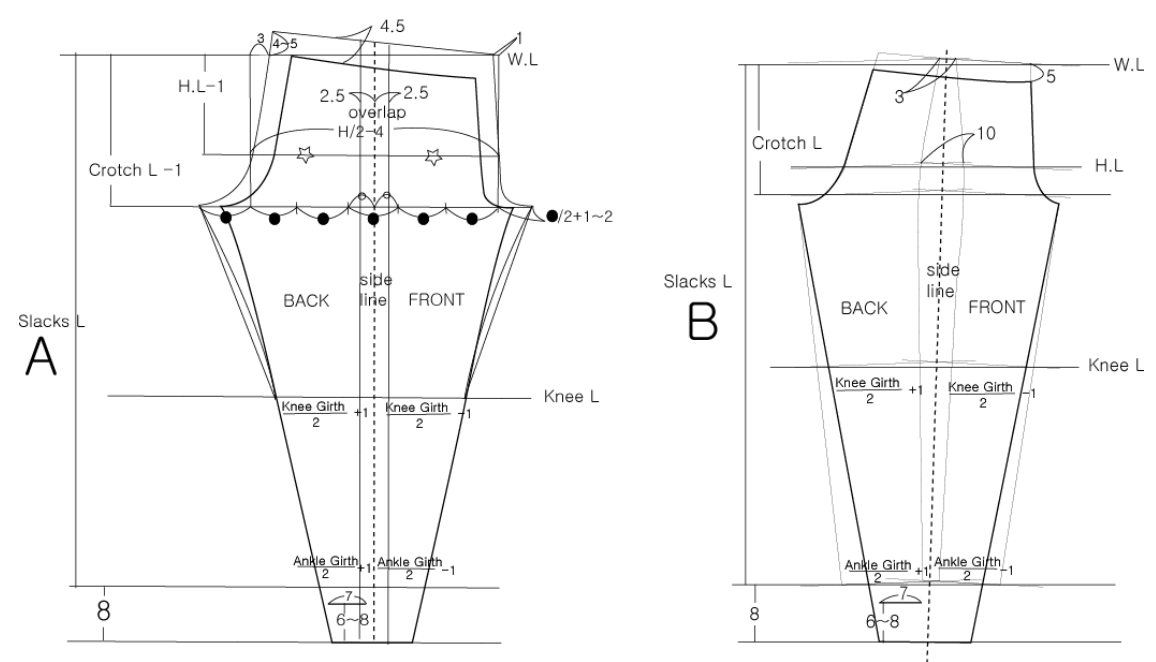

<Figure 1> Patterns of the Test Pants: Leggings Pattern by Oh, Sun-Hee ${ }^{11)}(A)$, and Jeans Pattern without dart by ESMOD ${ }^{12)}$ (B)

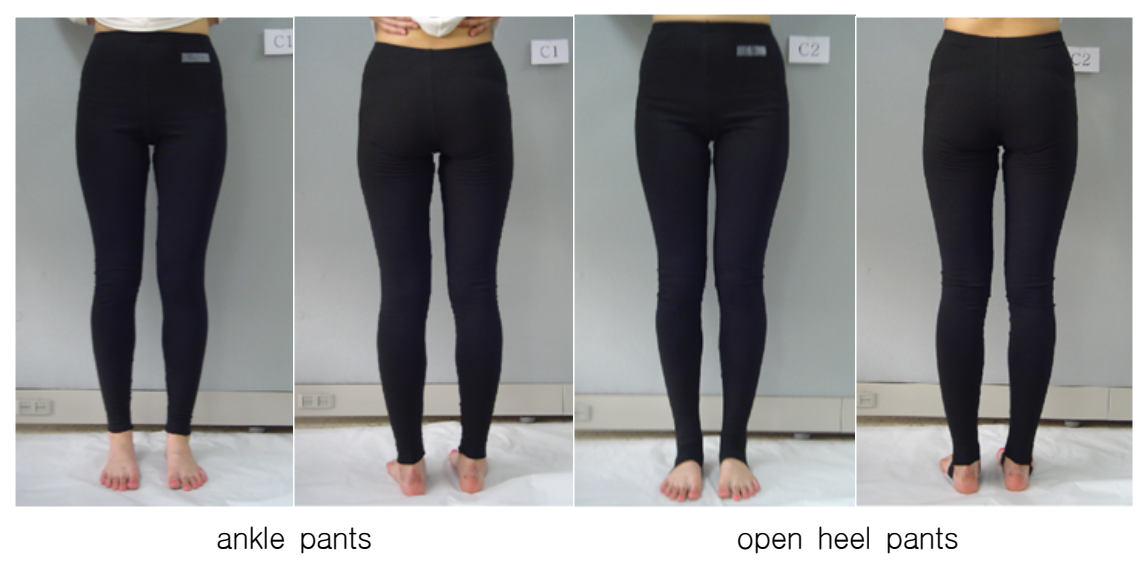

<Figure 2> The types of Test Pants and the Fitting Appearance at the Front and the Back 
Park Sanghee - Park Jinhee / A Study on the Comfort and the Patternmaking Method of Leggings Pants
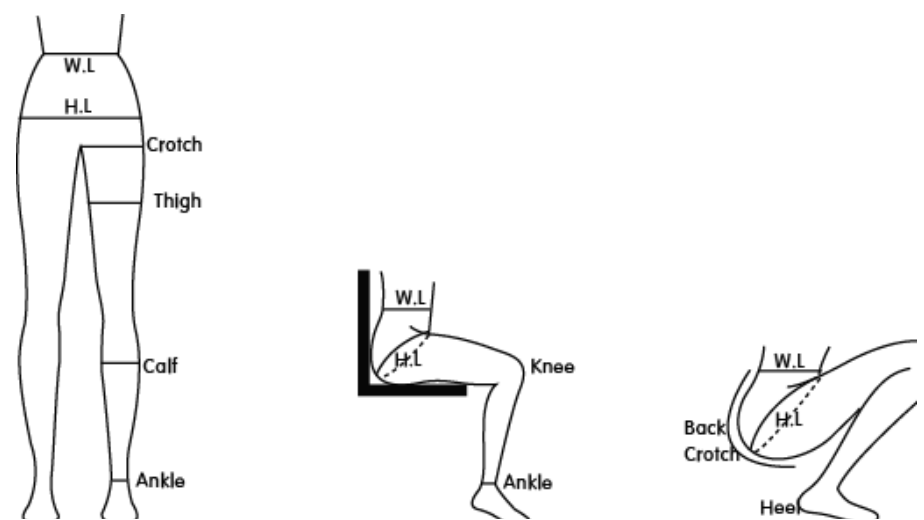

<Figure 3> Terms and Illustrations of Standing, Sitting, and Squatting postures

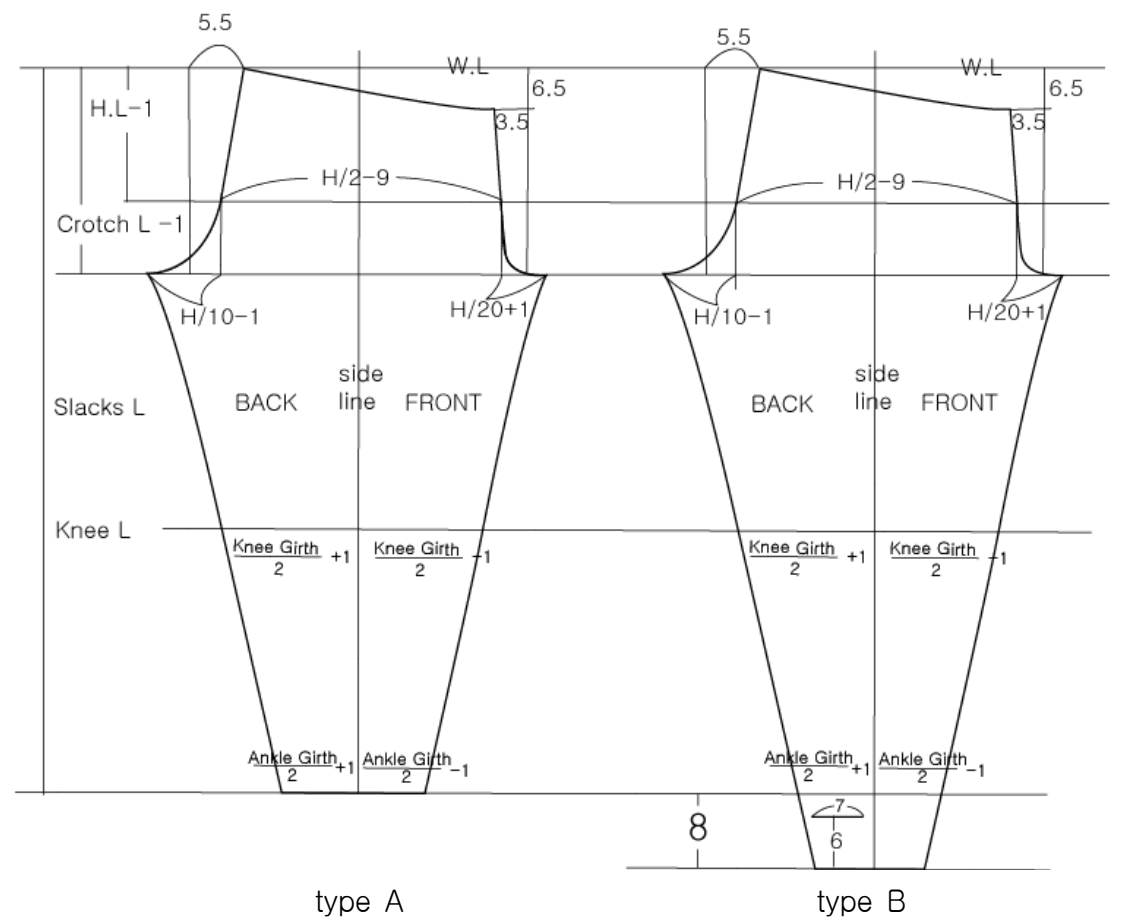

<Figure 4> type A - Ankle Pants, type B - Open Heel Pants

\section{Manufacturing Test Pants}

Two pairs of Test Pants - type A (ankle pants) and type $B$ (open heel pants) - are made on the basis of the pattern appreciated to be superb at the wear test, Leggings Pattern by Oh, Sun-Hee (A), with a little modifications at front rise length, position of heel openings, and so on. Modal fabric, which has good comfort, is selected for the material of Modal Pants. The wear test and the appearance test for the test Pants are done in the same way as done on the Test Pants. Consequently, through the tests, The Final prototype Pants are determined. 


\section{Consequences and the Analysis}

\section{The wear test of Leggings Pants on the market: The Preliminary Test}

The preliminary tests were executed on two kinds of leggings pants on the market: ankles pants and open heel pants each in three most popular materials: modal and cotton jersey; in a bit plump cotton twill span in ankle pants/ cotton knitted span in open heel pants. The ankle pants were made in three materials: rayon blend-modal(Rayon+P.E.), cotton jersey span (cotton jersey), and cotton twill span(twill). Cotton twill span leggings, which come in jeans style, are quite popular nowadays. The preliminary tests are composed of wear test and appearance evaluation. <Table $3>$ is about the wear tests on the comfort and degree of tension when the subjects are standing, sitting, and squatting.

The average values of the points given by the subjects at three postures are shown in <Table 3>.

Ankle pants made of cotton knitted span were shown to be loose on waist girth and thigh girth at standing posture, and unlike those in other kinds of materials, they were evaluated to be high at front waist and back waist. The overall length of the pants were reported to be lengthy, which will cause discomfort. At sitting posture, in cotton knitted span, back rise length was replied to be high; hip girth and knee girth appeared to be loose. In modal, ankle position was reported to be high. At squatting posture, in cotton knitted span, back rise length was too high causing inconvenience. As a whole, pants in cotton knitted span were evaluated to be lengthy in vertical direction, and generally loose in width in most of the parts.

Open heel pants made of modal were reported to have a proper tension at waist, hip, thigh, and calf at standing posture, while those in other materials were shown to be generally loose and especially at thigh and calf. Ankle areas were found to be a little tight in those of all materials. Front and back waist position appeared to be high in cotton jersey span and cotton knitted. As a whole, those in modal were likely to be more tightly fitting. At sitting posture, cotton jersey and cotton knitted showed a higher back rise length, and only modal revealed more tension at around knees. Ankle positions were high altogether, which desired to be improved to give more elasticity in vertical direction at knees. At squatting posture, in cotton jersey and cotton knitted, back rise length was reported to be high, showing the need to be adjusted. Cotton jersey and cotton knitted showed a loose hip girth and knees, the sizes which required to be reduced considering the elongation ratio of width around hip girth and knees. Modal pants were reported to be uncomfortable when feet are pushed through the ankle parts showing the need for the ankle girth to be lengthened.

$<$ Table $4>$ is about the appearance test on leggings pants on the market when the subjects are standing, sitting, and squatting. In the appearance test, ankle pants in modal at standing posture looked a little short, and at sitting posture back rise sag was only $0.6 \mathrm{~cm}$, which was very short compared to $6.5 \mathrm{~cm}$ in cotton span, so it looked very fine. At squatting posture, back rise sag was $2 \mathrm{~cm}$ in modal, $10 \mathrm{~cm}$ in cotton span, and $7 \mathrm{~cm}$ in cotton twill, which showed that modal makes the least sag at back rise to make pants comfortable as well as look most beautiful. Open heel pants in modal at standing posture looked low in waist and hip, and looked generally short. At sitting posture, 
Park Sanghee - Park Jinhee / A Study on the Comfort and the Patternmaking Method of Leggings Pants

back rise sag was found to be $2 \mathrm{~cm}$ in modal, $3.5 \mathrm{~cm}$ in cotton jersey, and $6.8 \mathrm{~cm}$ in cotton knitted. Still, the least sag made by modal was unrivaled. At squatting posture, back rise sag was noticed as $4.4 \mathrm{~cm}$ in modal, $7.2 \mathrm{~cm}$ in cotton jersey, and $9.5 \mathrm{~cm}$ in cotton knitted. Modal won the gold medal in terms of back rise sag, and cotton knitted recorded almost $10 \mathrm{~cm}$ sag proving to be incompetent to closely fit the body. It shows the same results that the most problematic parts in making and fitting pants using stretchable material is the rise length part. ${ }^{13)}$ The reason that heels are pulled upward in modal is probably because the pants are generally short. Most of leggings in modal on the market seemed to be short as a whole. However, modal must be a great material enough to be quite afformative to the movements of human body providing a pleasantly close fitness. On the other hand, cotton knitted is

$<$ Table 3> The classified wear test on Leggings Pants on the market

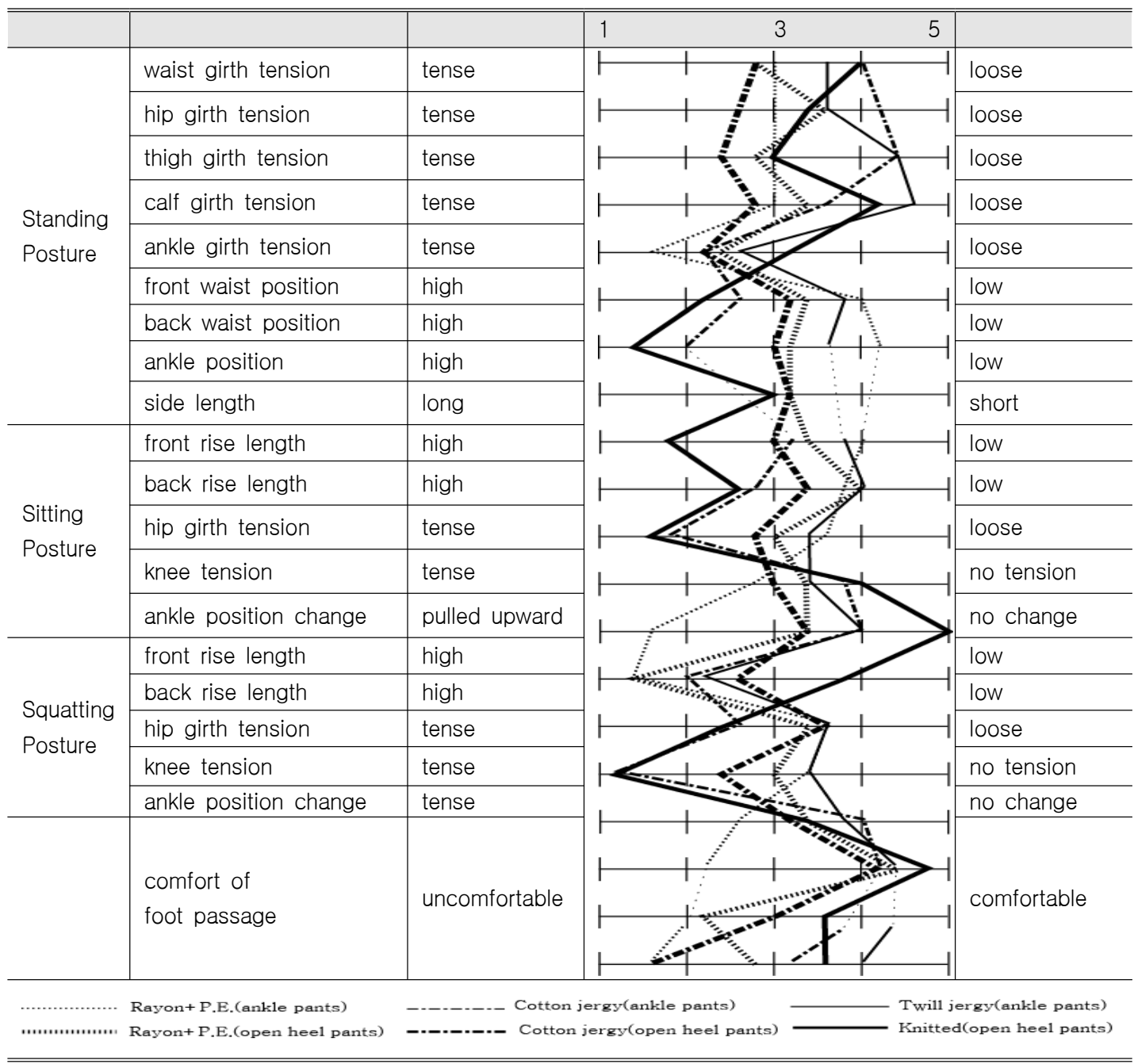


considered to be improper to be used for leggings pants which are supposed to fit the body closely.

By all the results of the preliminary tests, modal and cotton span materials were proved to be most acceptable. Thus, test pants are determined to be made of the two materials.

\section{The wear test for Test Pants}

In the wear test for open heel pants typed test pants, cotton span B pattern revealed looseness in waist, hip, thigh, and calf parts. Front waist position was noticed to be low in all the patterns, which points out that the waist line of the leggings is lower than real body waist line. This goes the same with ankle typed test pants. Overall length was evaluated to be short in cotton span materials in both patterns. At sitting posture, front rise length was high in all test pants. Ankle position changed upward in cotton pattern B. Heel position was lifted up in cotton span-pattern B. Foot passage at ankle area was uncomfortable in modal material. By and large, pattern $A$ was proved to be better than pattern $B$, and modal got the better evaluation in comfort over cotton span. <Table 5> shows that the classified wear test for test pants(open heel pants).

In the wear test for ankle pants typed test pants, cotton span B pattern unlike others turned out to be loose at waist, hip, thigh, and calf parts. Besides, the side length of it was reported to be generally short. Front waist position was equally low in all the materials showing that generally the waist line of leggings pants is lower than body waist line in design factor. At both sitting and squatting postures, front rise length were evaluated high in all the test pants, but the back rise length were considered

$<$ Table 4> The Appearance Test on Leggings Pants on the market

\begin{tabular}{|c|c|c|}
\hline & & 3 \\
\hline \multirow{4}{*}{$\begin{array}{l}\text { Standing } \\
\text { Posture }\end{array}$} & waist position & 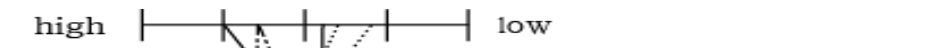 \\
\hline & hip girth line position & high $\longmapsto \mid$ low \\
\hline & side length & t 1 - short \\
\hline & ankle position & $\mid-1$ low \\
\hline \multirow{3}{*}{$\begin{array}{l}\text { Sitting } \\
\text { Posture }\end{array}$} & back rise sag & 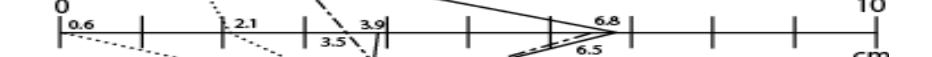 \\
\hline & knee tension & $\begin{array}{l}\text { no } \\
\text { tension }\end{array}$ \\
\hline & ankle position change & +1 no change \\
\hline \multirow{3}{*}{$\begin{array}{l}\text { Squatting } \\
\text { Posture }\end{array}$} & back rise sag & $72+1=0.26$ \\
\hline & knee tension & tense $\vdash \ldots$ \\
\hline & heel position change & $\begin{array}{l}\text { pulled } \\
\text { upward }\end{array}$ \\
\hline 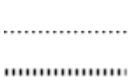 & $\begin{array}{l}\text { Rayon+ P.E.(ankle pants) } \\
\text { Rayon+ P.E.(open heel pants) }\end{array}$ & 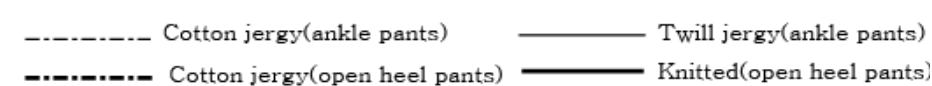 \\
\hline
\end{tabular}


Park Sanghee - Park Jinhee / A Study on the Comfort and the Patternmaking Method of Leggings Pants

$<$ Table 5> The classified wear test for test pants(open heel pants)

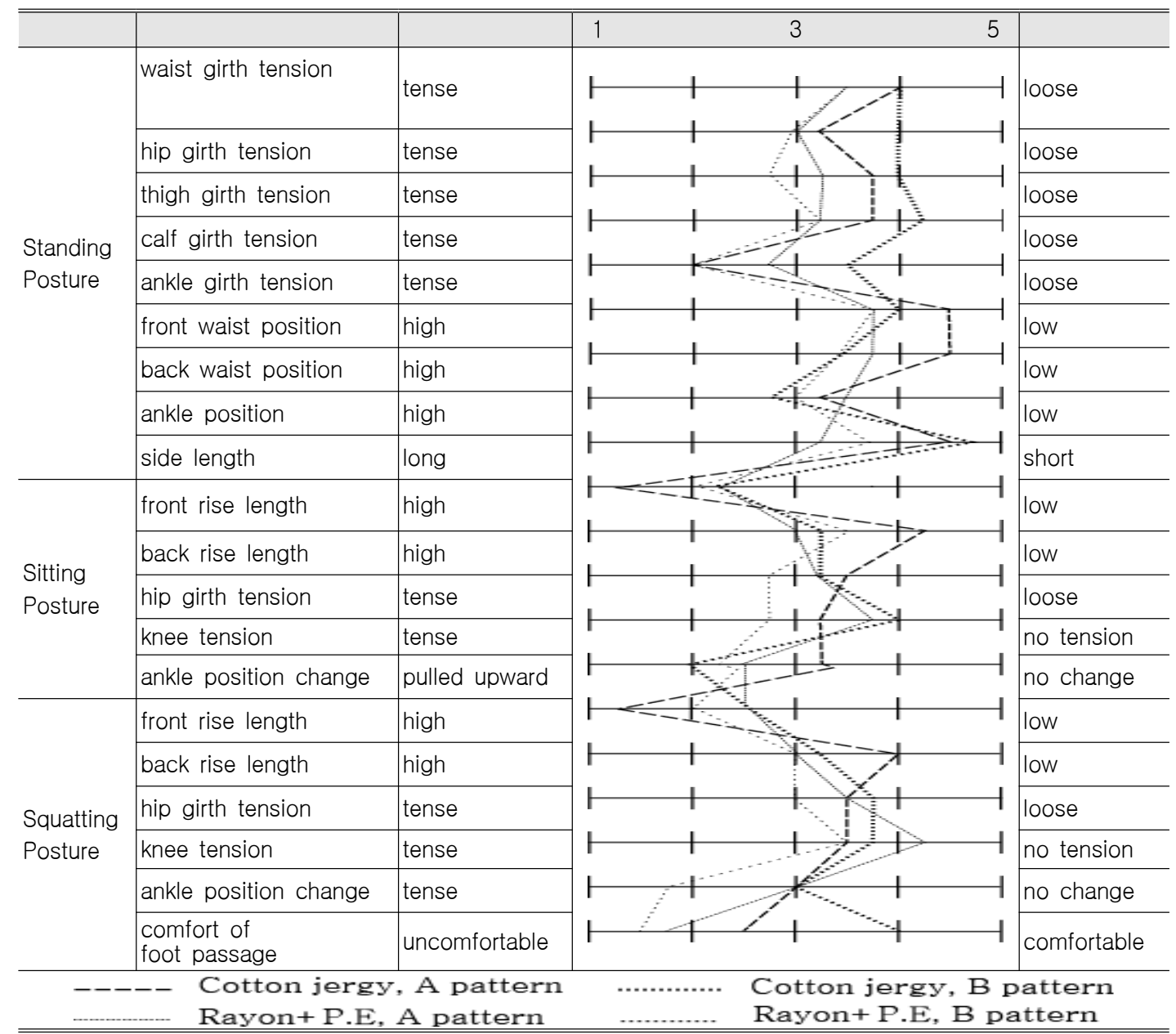

to be appropriate. <Table $6>$ is about the classified wear test for test pants(ankle pants).

In the appearance test for ankle pants typed test pants, at sitting posture, cotton span B pattern showed the biggest back rise sag, $4.3 \mathrm{~cm}$, and cotton span A pattern showed a significant degree of knee tension and ankle position change. At squatting posture, the biggest back rise sag was found in cotton span $B$ pattern $(6.6 \mathrm{~cm})$ and the least in cotton span A pattern $(4.6 \mathrm{~cm})$. Ankle position change was noticed less in modal pattern A.

In the appearance test for open heel pants typed test pants, at sitting posture, back rise sag was reported $2.3 \sim 3.5 \mathrm{~cm}$ in all the materials, which suggests that the test pants record better scores than those on the market did at the preliminary tests. Knee tension was seen to be proper only in modal A pattern. Ankle position is pulled upward in all the materials indicating ankle length has to be extended. At squatting posture, the least back rise sag was reported in 
$\langle$ Table 6> The classified wear test for test pants(ankle pants)

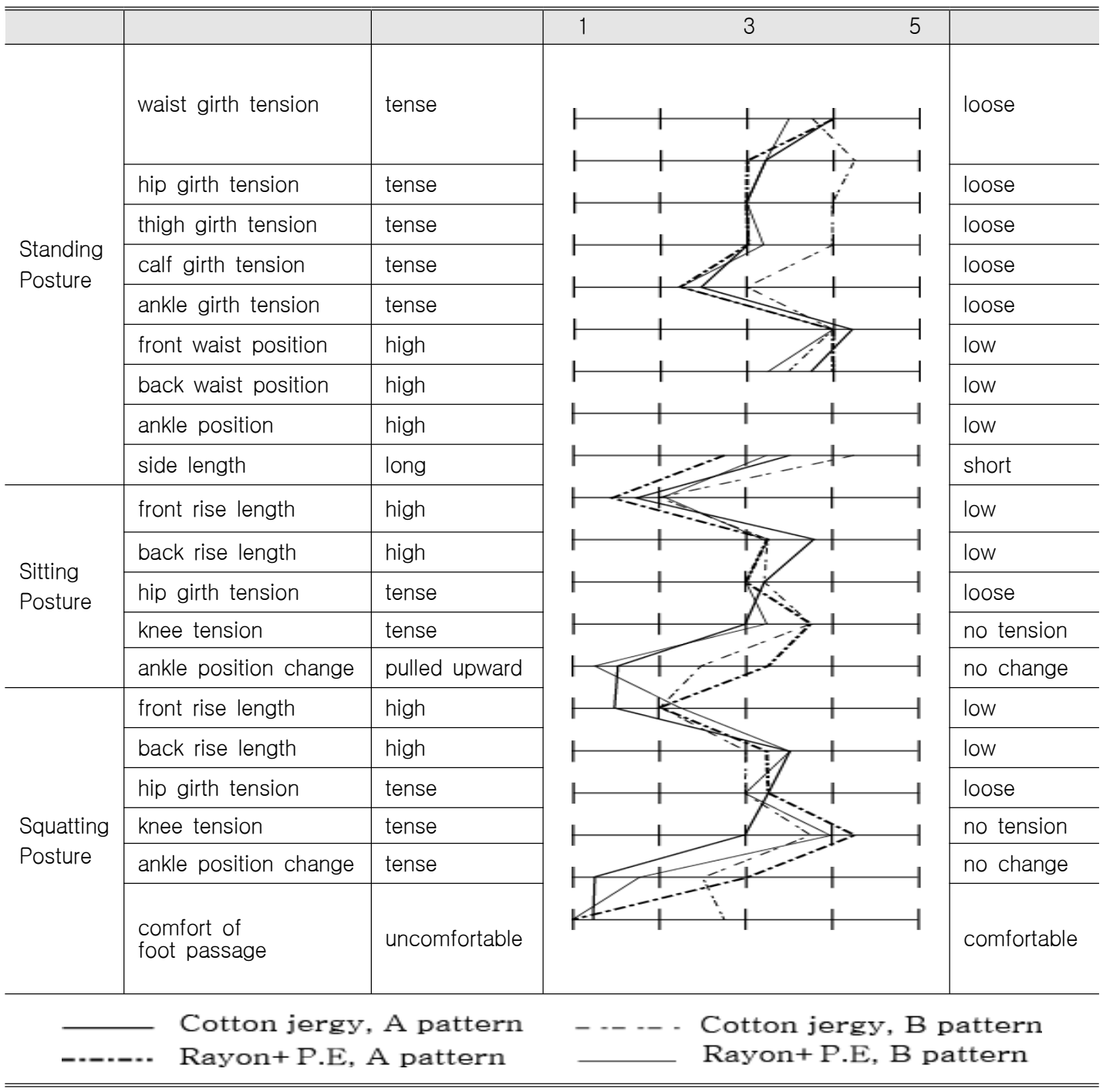

cotton span pattern A which was $4.8 \mathrm{~cm}$. As a whole, regardless of the length of the pants, pattern A showed better results in the appearance test. $\langle$ Table 7$\rangle$ is about the appearance test for test pants.

\section{The wear test for Model Pants}

Model pants were made on the basis of the test pants with proper modifications such as lowering front waist line by $2 \mathrm{~cm}$ which was turned out by the previous tests, and shifting down the position of the heel openings to $6 \mathrm{~cm}$ away from the leg openings. Model pants were 
Park Sanghee - Park Jinhee / A Study on the Comfort and the Patternmaking Method of Leggings Pants

$\langle$ Table 7$\rangle$ The appearance test for test pants

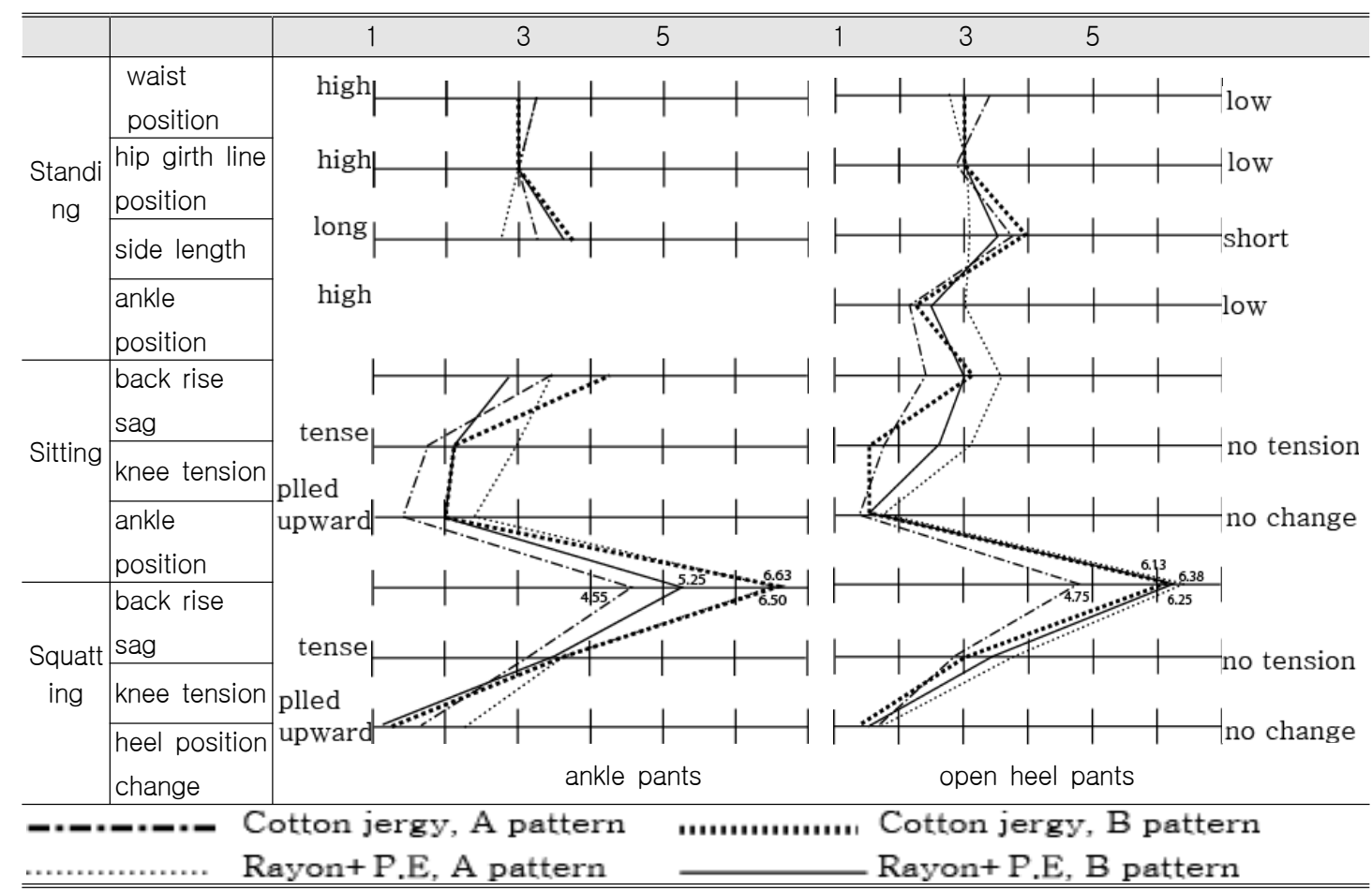

made basically with the pattern of Leggings Pattern by Oh, Sun-Hee (A) which was evaluated to be the best on the whole. Two kinds of test pants were made: type A (ankle pants type) and type $B$ (open heel pants type). <Figure 4 > shows that type A - Ankle Pants and type B - Open Heel Pants.

Through the wear test of model pants, both ankle pants and open heel pants typed pants were evaluated to have been pretty much improved in most of the parts. At standing posture, the degree of tension was reported to be proper in each part, and the overall length was also properly modified. At both sitting and squatting postures, front rise length, which was low in the previous tests, was adequately adjusted. The excessive tension at knee area was moderately adjusted and the discomfort owing to the change of heel positions while moving was also satisfactorily relieved. <Table 8> showed the results of the classified wear test for model pants. Thus, after all these tests and betterments much of the defects and discomfort were treated to end up getting a desirable combination of good material and pattern for stretch pants.

All the results concerned, modal material is considered to be a better option between the two most popular materials, cotton span and modal, of leggings on the market. For pattern's sake, Oh, Sun-Hee's pattern is assumed quite acceptable, though still leaving room for improvement, which was by far able to be settled through this study. 
$<$ Table 8> The classified wear test for Model pants

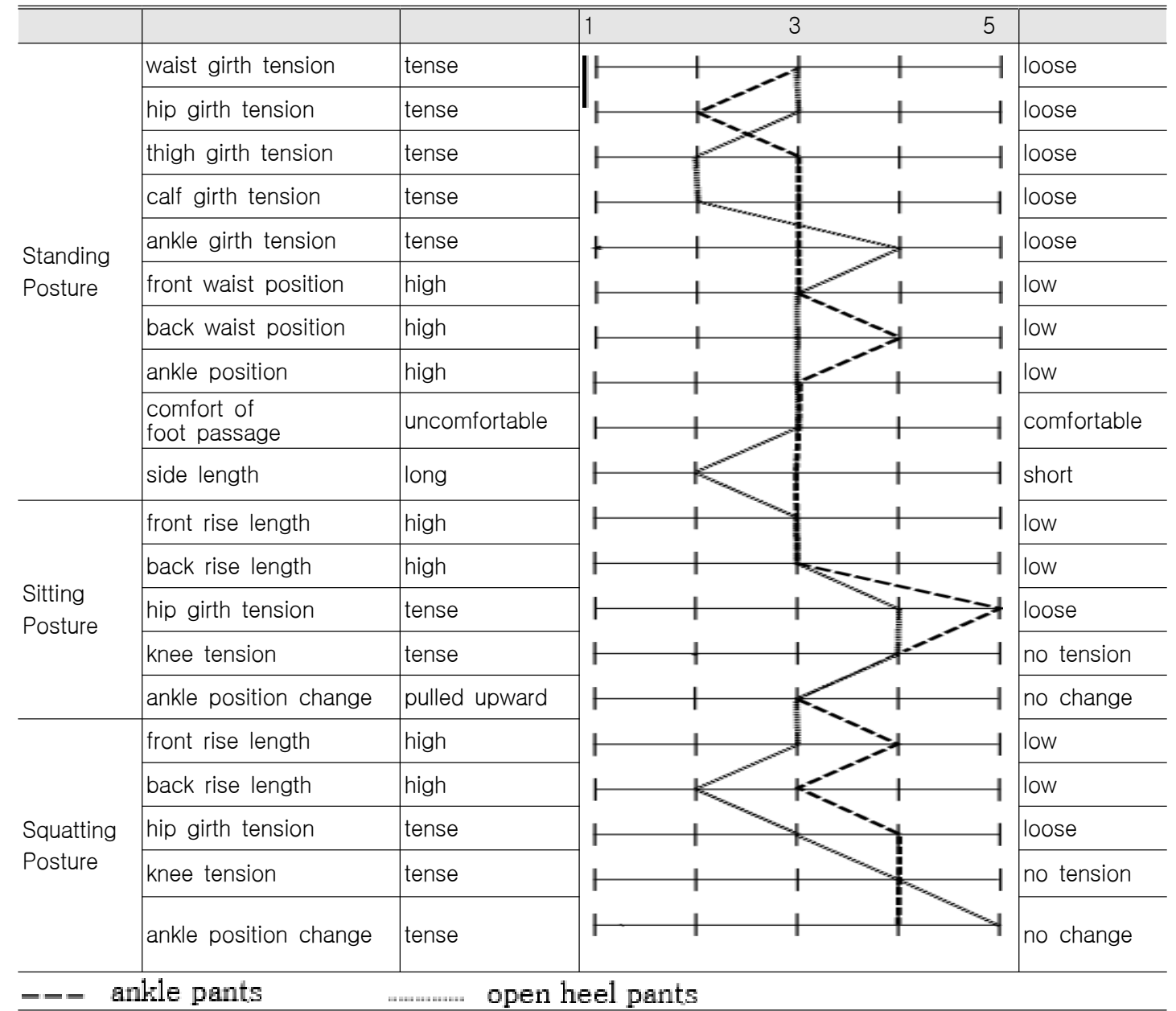

\section{Conclusion}

Out of the popular leggings pants on the market selected were four kinds according to material and two kinds by types, through the fitness and appearance tests of which two kinds of test pants were made. And in turn, the test pants were put to the same tests as earlier in order to find out good things and bad things about the pants, which were all counted in making the most desirable model pants. The findings from the study are summarized as follows:

1. According to the results of the wear test and appearance test on 8 leggings pants (4 kinds of materials by 2 kinds of types), pants made of modal fabric have proper tension in each part of the pants; those made of cotton knitted span are generally loose; those of cotton jersey are somewhat too high at the back waist line and are loose in hip and knee parts. At 
Park Sanghee - Park Jinhee / A Study on the Comfort and the Patternmaking Method of Leggings Pants

sitting posture, all the pants showed a tendency for their ankle positions to be pulled upward.

2. The results of the appearance test of the leggings pants show that modal fabric is the best material for stretch pants in that they make the least amount of sag in back rise, which is beautiful and comfortable as well. On the other hand, cotton knitted span is proved to be incapable of holding the body to make a good fitness. Therefore, modal and cotton span are relatively favorably evaluated.

3. Through the wear test on test pants made according to 2 kinds of patterns, 2 kinds of materials, and 2 kinds of types, it was revealed that front waist line is somewhat high at standing posture and front rise length is long at squatting posture, which is found in pants made in all patterns and types. Pants made of cotton span in pattern $B$ are likely to be loose in every part and ankle position is pulled upward in moving. Pants made of modal fabric have their heel parts strained in activity.

4. In the appearance test for the test pants, all the patterns show the tendency that heel position changes upward, so that heel position should be lowered. Sagging in the back rise is the most severe in cotton span and pattern B, though it is not as much as those on the market. It shows betterness than in the test of market leggings. Pattern A gets good marks in general.

5. The wear test of model pants suggests that major discomfort problems are settled by the previous tests and adjustments. Fitness in every part at standing posture is adequate and overall length is proper. In sitting and squatting posture, there seems no severe uncomfortableness.

This study is intended to observe female leggings pants on the market in order to understand and settle the current problems within them. Furthermore, it has been tried to propose a model design with desirable material and pattern.

\section{Reference}

1) "Stretch Material PBT Rush",(1997, Feb. 20), Korea Fashion \& Textile News, p.5.

2) Huh Jihye(1998), "Pattern Design Method of Tops on the Elasticity of Knit", Master's Degree Thesis, Yonsei University Graduate School, p.7.

3) Jung Jaeeun, Nam Yoonja(1999), "A Study on the Physical Satisfaction of themselves and Ideal Types of Women in their Twenties", Journal of the Korean Society of Clothing and Textiles, 23(1), pp.159-169.

4) Lee Minjeong, Sohn Heesoon(2012), "Basic Research on the Development of Skinny Jean Pants for Korean Women in Their 20s+", Journal of Fashion Business, 16(6), pp.160- 173.

5) Sung OKjin, Kim Aerin(2003), "A Study on a Model of Slacks using Stretch Material with change of shapes according to the direction of elongation", Life Science, 6th issue, pp.215-231.

6) Sewing Institute of Che-il Industries(1997), Methods of Sewing of Stretch Fabrics, pp.12-15.

7) Chun Jongsuk, Seok Eunyoung, Park Soonji(1998), "A Case Study on the Methods of Applying Elasticity of Fabrics to Model Designing", Journal of the Korean Society of Clothing and Textiles, 22(2), pp.188-192.

8) Jung Heesoon(1998), "A Study on Slacks using fabric extensibility : for young women", Master Degree Thesis, Seoul National University Graduate School, p.15. 
Journal of Fashion Business Vol.17, No.3

9) Kim Soonboon(2004), "Designing a model of tight pants for modern dance made of stretch material", Journal of the Korean Home Economics Association, 42(4), pp. 45-54.

10) Size Korea 2004, Retrieved 2011.11.10, from http://sizekorea.kats.go.kr/

11) Oh Seonhee(2000), Western Clothing Construction, Seoul Yehaksa, p.86.

12) Marie-Noëlle, Patricia Trouver(1990), Pattern Making Manuel, Paris: ESMOD, p.23.

13) Kim Aerin(2002), "A Study on the Development of Clothes Pattern for Stretch Material - Survey on the Apparel made of Stretch Material for Females in their Twenties -", Life Science, 5th issue, pp.131-142.

Received (Jun. 13, 2013)

Revised (Jun. 25, 2013, Jul. 3, 2013)

Accepted (Jul. 7, 2013) 